\title{
Analysis of Vibration Natural Frequencies of Rotationally Restrained and Simply Supported Circular Plate with Weakened Interior Circle Due to an Angular Crack
}

\author{
L. Bhaskara Rao ${ }^{\mathrm{a}, 1}$ and C. Kameswara Rao ${ }^{\mathrm{b}, 2}$ \\ ${ }^{\text {a }}$ School of Mechanical and Building Sciences, VIT University, Chennai, Tamil Nadu, India \\ b Nalla Narsimha Reddy Engineering College, Ranga Reddy, Hyderabad, India \\ ${ }^{1}$ bhaskarbabu_20@yahoo.com \\ 2 chellapilla95@gmail.com
}

УДК 539.4

\section{Анализ собственных частот колебаний шарнирно закрепленной круговой пластины с ограничением по вращению, ослабленной круговой трещиной}

\author{
Л. Бхаскара Раo \\ a Технологический институт Веллоре, Ченнай, Тамилнад, Индия \\ ${ }^{\sigma}$ Налла Нарсимха Редди технический колледж, Рангаредди, Хайдарабад, Индия
}

Получено точное решение для описания колебаний шарнирно закрепленной по внешнему краю круговой пластины с ограничением по вращению, которая ослаблена круговой трещиной. Рассчитаны частоты шести первых мод колебаний пластины для различных значений упругих характеристик шарнирного защемления, радиуса круговой трещины и степени ослабления пластины трещчиной. Наличие трещины моделируется в виде фиктивного упругого закрепления пластины по линии трещины. Показано, что ослабление пластины трещиной приводит к снижению собственной частоты колебаний на 30\%. Предполагается, что использование результатов точного решения является перспективным при оценке влияния трещины на колебания круговой пластины с внешним шарнирным закреплением и ограничением по врашению и верификации данных, полученных приближенными численными методами, включая метод конечных элементов.

Ключевые слова: круговая пластина, частота, ограничение по вращению, ослабленная пластина.

\section{Notation}

$D \quad-$ flexural rigidity

$K_{R 1}$ - rotational spring stiffness at the outer edge

$K_{R 2}-$ rotational spring stiffness in the cracked region

$R_{11} \quad$ - non-dimensional rotational flexibility parameter at the outer edge

$R_{22}$ - non-dimensional rotational flexibility parameter in the cracked region

$k \quad-$ non-dimensional frequency parameter

Introduction. Vibration of circular plates is of great importance in structural design for dynamical loads [1-6]. The problem of free vibrations of uniform isotropic circular plates with classical boundary conditions and internal strengthening has been studied in 
detail [7-9]. Cawley and Adams [10] analyzed cracked circular plates by suitably diminishing the values of elastic coefficients of the respective finite element at the nodal location of the crack. Markström and Storákers [11] used the method of unravelling the nodes of the respective finite elements along the face of the crack. Aggarwala and Ariel [12] computed the natural frequencies of cracked circular plates with simply supported boundary conditions by utilizing the second kind of homogeneous Fredholm integral.

Leissa et al. [13] studied the influence of V-notches of different angles and depths on the dynamic behavior of circular plates that are completely free at their boundaries. McGee et al. [14] investigated the free vibrations of thin circular plates with free or rigidly constrained V-notches. Using the Ritz method, Yuan and Dickinson [15] investigated the free vibrations of circular, annular and sector plates, which were partially supported along their boundaries or had sectorial cut-outs. Van Rens et al. [16] studied the behavior of perforated plates by tuning the properties of the homogenized plate to be equal to the global properties of the same plate. Huang et al. [17] examined the effect of cracks on the dynamic characteristics of a vibrating circular plate with free edge and a radial crack initiated from the boundary by using an optical system called the AF-ESPI method with out-of-plane displacement. Krawczuk et al. [18] presented a finite element elastoplastic model of a plate having a through crack. Li et al. [19] studied the vibrational power flow characteristics of circular plates having a surface crack at the periphery. Shi et al. [20] computed the eigenfrequency of a cracked circular clamped baffled plate in contact with water and obtained NAVMI factor for each mode of vibration using the method of iteration. Kim and Jung [21] obtained the eigenfrequencies of free edge-rhombus plates with V-notches using a similar method of iteration. Demir and Mermertas [22, 23] studied the natural frequencies of annular plates with radial periodic through cracks and angular cracks by using sector finite elements. Recently, Huang and Leissa [24] studied the influence of side cracks on the eigenfrequencies and mode shapes of plates of rectangular shape with simply supported or completely free boundary conditions. Liu et al. [25] studied the crack influence on the dynamic characteristics of a perforated plate in contact with water using the ANSYS software.

Utilizing the Mindlin thick plate theory, Huang et al. [26] implemented the Ritz method to accurately determine the frequencies and nodal patterns of cracked rectangular plates. Using the Rayleigh-Ritz method, Si et al. [27-29] studied the free vibration behavior of a completely clamped cracked circular plate, a baffled cracked circular plate, and a cracked rectangular plate, respectively, considering the influence of water on one side. Chen et al. [30] studied the vibration characteristics of a cantilever rectangular plate with side crack using Ritz method. Chen et al. [31, 32] performed mathematical analysis and numerical study of true and spurious eigenequations for free vibration of plates using the imaginary-part boundary element method (BEM). Lee et al. [33] performed the analytical study and numerical experiments of true and spurious eigensolutions of free vibration of circular plates using the real-part BEM. Lee et al. [34-37] performed the analysis of a circular plate with multiple holes by using indirect BIEMs, the multipole Trefftz method, the direct BIEM and the addition theorem, respectively.

However, weakening of a plate may be induced by the presence of partial cracks and internal notching. Only two papers authored by Wang [38] and Yu [39] dealing with free vibration characteristics of circular plates with internal and having simply supported or clamped boundary conditions, as well as movable or free edge conditions, respectively, could be found in the available literature In both studies, the weakened portion was modeled as a hinge with an appropriately computed rotational restraint parameter depending upon the characteristics of the crack present in the plate. Even though the circular symmetry of the plate permits for a substantial interpretation of the problem, very often difficulties escalate due to the intricacy of the respective boundary condition involved. Here the complexity is due to realistic situations where boundary conditions are 
complex and do not fall under the usual classical boundary conditions. Using the appropriate elastic linear and rotational restraints [40-43], solutions for these complex boundary conditions can be obtained. In a recent study of Bhaskara Rao and Kameswara Rao [44], the vibrations of circular plates weakened along the interior circle and with elastic edge restrictions against translation were analyzed.

As per authors' knowledge, no other research paper addressing the non-classical complex boundary conditions, such as rotationally restrained and simply supported condition at the edge of plate, has yet been published. Therefore, the aim of this paper is to study the effect of weakening of a rotationally restrained and simply supported along the outer edge thin circular plate along a concentric circle due to an angular crack by using the exact method of solution approach. Here, the angular crack is modeled as a hinge with a rotational restraint parameter, while the natural frequencies of a circular plate for different values of the rotational restraint parameter along the plate edge, the radius of the weakened circle, Poisson's ratio and the rotational restraint with hinge of the cracked region are obtained for the further use in the design of cracked and weakened circular plates, which are applied in engineering, e.g., in the design of doors and hatches used in aircraft and spacecraft, as well as in vibration control and structural design.

1. Analytical Formulations. The plate is rotationally restrained and simply supported at the outer edge, i.e., at a radius of $R$ from the center, as shown in Fig. 1. The radius of the weakened circle because of crack is considered as $b R$, where $b$ is only a fraction of 1 . Here, all lengths are normalized with respect to $R$, i.e., the radius of the outer region is 1 , while the radius of the inner cracked region is $b$. The subscript $I$ corresponds to the outer region $b \leq r \leq 1$, and subscript $I I$ to the inner region $0 \leq r \leq b$. Here, $h, v, R$, and $E$ represent the plate thickness, Poisson's ratio, radius, and elastic modulus, respectively.
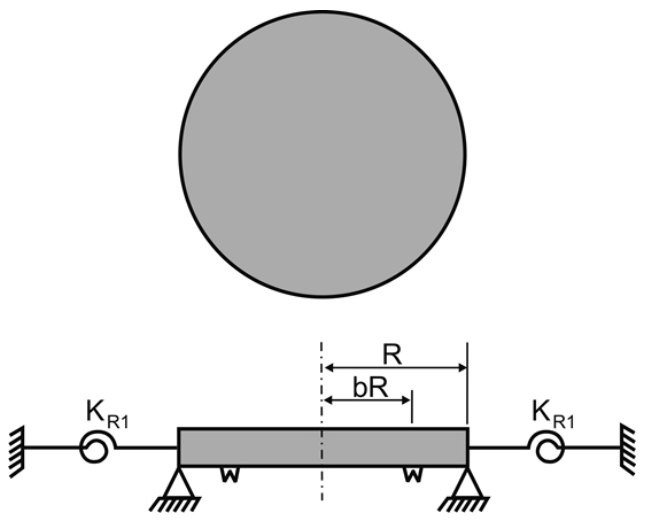

Fig. 1. A circular plate with rotationally restrained and simply supported edge and an angular crack.

The general form of the lateral displacement of vibration of a classical plate can be expressed as $w=u(r) \cos (n \theta) e^{i \Omega t}$, where $(r, \theta)$ are polar coordinates, $n$ is the number of modal diameters, $w$ is transverse displacement, $\Omega$ is frequency, and $t$ is time. The function $u(r)$ is a linear combination of the Bessel functions $J_{n}(k r), Y_{n}(k r), I_{n}(k r)$, and $K_{n}(k r)$, and $k=R\left(\rho \Omega^{2} / D\right)^{1 / 4}$, where $k$ is the square root of non-dimensional frequency [2] and $\rho$ is the density. General solution for regions I and II are as follows:

$$
\begin{gathered}
u_{I}(r)=C_{1} J_{n}(k r)+C_{2} Y_{n}(k r)+C_{3} I_{n}(k r)+C_{4} K_{n}(k r), \\
u_{I I}(r)=C_{5} J_{n}(k r)+C_{6} I_{n}(k r),
\end{gathered}
$$


where $r$ designates the distance measured from the center of plate, whose maximum value is $R$. Considering a simply supported and rotationally restrained outer edge, the boundary conditions at outer edge are

$$
\begin{gathered}
M_{r}(r, \theta)=K_{R 1} \frac{\partial w_{I}(r, \theta)}{\partial r}, \\
w_{I}(r, \theta)=0,
\end{gathered}
$$

where the bending moment is defined as

$$
M_{r}(r, \theta)=-\frac{D}{R}\left[\frac{\partial^{2} w_{I}(r, \theta)}{\partial r^{2}}+v\left(\frac{1}{r} \frac{\partial w_{I}(r, \theta)}{\partial r}+\frac{1}{r^{2}} \frac{\partial^{2} w_{I}(r, \theta)}{\partial \theta^{2}}\right)\right] .
$$

Equations (3) and (5) yield the following expression:

$$
\left[\frac{\partial^{2} w_{I}(r, \theta)}{\partial r^{2}}+v\left(\frac{1}{r} \frac{\partial w_{I}(r, \theta)}{\partial r}+\frac{1}{r^{2}} \frac{\partial^{2} w_{I}(r, \theta)}{\partial \theta^{2}}\right)\right]=K_{R 1} \frac{\partial w_{I}(r, \theta)}{\partial r} .
$$

Equations (4) and (6) can be expressed as

$$
\begin{gathered}
u_{I}^{\prime \prime}(r)+v\left[u_{I}^{\prime}(r)-n^{2} u_{I}(r)\right]=-R_{11} u_{I}^{\prime}(r), \\
u_{I}(r)=0,
\end{gathered}
$$

where $R_{11}=K_{R 1} R / D$ is the normalized spring constant $K_{R 1}$ of the rotational spring stiffness.

At $r=b$, the plate, except for the slope, is continuous in terms of displacement, moment, and shear, whereas the continuity requirement [38] at the interface of regions I and II can be formulated as

$$
\begin{gathered}
u_{I}(b)=u_{I I}(b), \\
b u_{I}^{\prime \prime}(b)+v u_{I}^{\prime}(b)=b u_{I I}^{\prime \prime}(b)+v u_{I I}^{\prime}(b), \\
b^{2} u_{I}^{\prime \prime \prime}(b)-\left[1+n^{2}(2-v)+v\right] u_{I}^{\prime}(b)=b^{2} u_{I I}^{\prime \prime \prime}(b)-\left[1+n^{2}(2-v)+v\right] u_{I I}^{\prime}(b) .
\end{gathered}
$$

The moment is set to be proportional to the difference of the slopes

$$
b^{2} u_{I I}^{\prime \prime}(b)+v\left[b u_{I I}^{\prime}(b)-n^{2} u_{I I}(b)\right]=b^{2} R_{22}\left[u_{I}^{\prime}(b)-u_{I I}^{\prime}(b)\right],
$$

where $R_{22}=K_{R 2} R / D$ is the normalized spring constant and $K_{R 2}$ is the rotational spring stiffness, which is utilized for modeling the rotational restraint created by the angular crack at $r=b$. Damage detection experiments can establish the values of rotational stiffness of the crack by matching the theoretically estimated frequency with the one obtained from the experimental studies. Evidently, the stiffness coefficient value $K_{R 2}$ depends on the crack depth and inclination angle. The non-trivial solutions to Eqs. (7)-(12) are sought. Eventually, Eqs. (1), (2) and (7)-(12) yield the following dependencies: 


$$
\begin{aligned}
& {\left[\frac{k}{2}\left[(v)+R_{11}\right] P_{1}+\frac{k^{2}}{4} P_{2}-\left(\frac{k^{2}}{2}+v n^{2}\right) J_{n}(k)\right] C_{1}+} \\
& +\left[\frac{k}{2}\left[(v)+R_{11}\right] Q_{1}+\frac{k^{2}}{4} Q_{2}-\left(\frac{k^{2}}{2}+v n^{2}\right) Y_{n}(k)\right] C_{2}+ \\
& +\left[\frac{k}{2}\left[(v)+R_{11}\right] R_{1}+\frac{k^{2}}{4} R_{2}+\left(\frac{k^{2}}{2}-v n^{2}\right) I_{n}(k)\right] C_{3}+ \\
& +\left[\frac{k}{2}\left[(v)+R_{11}\right] S_{1}-\frac{k^{2}}{4} S_{2}-\left(\frac{k^{2}}{2}-v n^{2}\right) K_{n}(k)\right] C_{4}=0, \\
& {\left[J_{n}(k)\right] C_{1}+\left[Y_{n}(k)\right] C_{2}+\left[I_{n}(k)\right] C_{3}+\left[K_{n}(k)\right] C_{4}=0,} \\
& {\left[J_{n}(k b)\right] C_{1}+\left[Y_{n}(k b)\right] C_{2}+\left[I_{n}(k b)\right] C_{3}+\left[K_{n}(k b)\right] C_{4}-} \\
& -\left[J_{n}(k b)\right] C_{5}-\left[I_{n}(k b)\right] C_{6}=0, \\
& {\left[\frac{b k^{2}}{4} P_{2}^{\prime}+\frac{v k}{2} P_{1}^{\prime}-\frac{b k^{2}}{2} J_{n}(k b)\right] C_{1}+\left[\frac{b k^{2}}{4} Q_{2}^{\prime}+\frac{v k}{2} Q_{1}^{\prime}-\frac{b k^{2}}{2} Y_{n}(k b)\right] C_{2}+} \\
& +\left[\frac{b k^{2}}{4} R_{2}^{\prime}+\frac{v k}{2} R_{1}^{\prime}+\frac{b k^{2}}{2} I_{n}(k b)\right] C_{3}+\left[\frac{b k^{2}}{4} S_{2}^{\prime}-\frac{v k}{2} S_{1}^{\prime}+\frac{b k^{2}}{2} K_{n}(k b)\right] C_{4}- \\
& -\left[\frac{b k^{2}}{4} P_{2}^{\prime}+\frac{v k}{2} P_{1}^{\prime}-\frac{b k^{2}}{2} J_{n}(k b)\right] C_{5}-\left[\frac{b k^{2}}{4} R_{2}^{\prime}+\frac{v k}{2} R_{1}^{\prime}+\frac{b k^{2}}{2} I_{n}(k b)\right] C_{6}=0, \\
& {\left[\frac{b^{2} k^{3}}{8} P_{3}^{\prime}-\frac{k}{2}\left(\frac{3 b^{2} k^{2}}{4}+\left(1+n^{2}(2-v)+v\right)\right) P_{1}^{\prime}\right] C_{1}+} \\
& +\left[\frac{b^{2} k^{3}}{8} Q_{3}^{\prime}-\frac{k}{2}\left(\frac{3 b^{2} k^{2}}{4}+\left(1+n^{2}(2-v)+v\right)\right) Q_{1}^{\prime}\right] C_{2}+ \\
& +\left[\frac{b^{2} k^{3}}{8} R_{3}^{\prime}+\frac{k}{2}\left(\frac{3 b^{2} k^{2}}{4}-\left(1+n^{2}(2-v)+v\right)\right) R_{1}^{\prime}\right] C_{3}+ \\
& +\left[-\frac{b^{2} k^{3}}{8} S_{3}^{\prime}+\frac{k}{2}\left(-\frac{3 b^{2} k^{2}}{4}+\left(1+n^{2}(2-v)+v\right)\right) S_{1}^{\prime}\right] C_{4}+ \\
& +\left[\frac{b^{2} k^{3}}{8} P_{3}^{\prime}+\frac{k}{2}\left(\frac{3 b^{2} k^{2}}{4}+\left(1+n^{2}(2-v)+v\right)\right) P_{1}^{\prime}\right] C_{5}+
\end{aligned}
$$




$$
\begin{gathered}
+\left[-\frac{b^{2} k^{3}}{8} R_{3}^{\prime}+\frac{k}{2}\left(-\frac{3 b^{2} k^{2}}{4}+\left(1+n^{2}(2-v)+v\right)\right) R_{1}^{\prime}\right] C_{6}=0, \\
{\left[\frac{b^{2} k R_{22}}{2} P_{1}^{\prime}\right] C_{1}+\left[\frac{b^{2} k R_{22}}{2} Q_{1}^{\prime}\right] C_{2}+\left[\frac{b^{2} k R_{22}}{2} R_{1}^{\prime}\right] C_{3}-\left[\frac{b^{2} k R_{22}}{2} S_{1}^{\prime}\right] C_{4}-} \\
-\left[\frac{b^{2} k^{2}}{4} P_{2}^{\prime}+\frac{k b}{2}\left(v+b R_{22}\right) P_{1}^{\prime}-\left(\frac{b^{2} k^{2}}{2}+n^{2}\right) J_{n}(k b)\right] C_{5}- \\
-\left[\frac{b^{2} k^{2}}{4} R_{2}^{\prime}+\frac{k b}{2}\left(v+b R_{22}\right) R_{1}^{\prime}+\left(\frac{b^{2} k^{2}}{2}-n^{2}\right) I_{n}(k b)\right] C_{6}=0,
\end{gathered}
$$

where

$$
\begin{array}{ccc}
P_{1}=J_{n-1}(k)-J_{n+1}(k), & P_{2}=J_{n-2}(k)+J_{n+2}(k), & P_{3}=J_{n-3}(k)-J_{n+3}(k), \\
Q_{1}=Y_{n-1}(k)-Y_{n+1}(k), & Q_{2}=Y_{n-2}(k)+Y_{n+2}(k), & Q_{3}=Y_{n-3}(k)-Y_{n+3}(k), \\
R_{1}=I_{n-1}(k)+I_{n+1}(k), & R_{2}=I_{n-2}(k)+I_{n+2}(k), & R_{3}=I_{n-3}(k)+I_{n+3}(k), \\
S_{1}=K_{n-1}(k)+K_{n+1}(k), & S_{2}=K_{n-2}(k)+K_{n+2}(k), & K_{3}=K_{n-3}(k)+K_{n+3}(k), \\
P_{1}^{\prime}=J_{n-1}(k b)-J_{n+1}(k b), & P_{2}^{\prime}=J_{n-2}(k b)+J_{n+2}(k b), & P_{3}^{\prime}=J_{n-3}(k b)-J_{n+3}(k b), \\
Q_{1}^{\prime}=Y_{n-1}(k b)-Y_{n+1}(k b), & Q_{2}^{\prime}=Y_{n-2}(k b)+Y_{n+2}(k b), & Q_{3}^{\prime}=Y_{n-3}(k b)-Y_{n+3}(k b), \\
R_{1}^{\prime}=I_{n-1}(k b)+I_{n+1}(k b), & R_{2}^{\prime}=I_{n-2}(k b)+I_{n+2}(k b), & R_{3}^{\prime}=I_{n-3}(k b)+I_{n+3}(k b), \\
S_{1}^{\prime}=K_{n-1}(k b)+K_{n+1}(k b), \quad S_{2}^{\prime}=K_{n-2}(k b)+K_{n+2}(k b),
\end{array}
$$

2. Results and Discussion. The above equations are used to obtain the exact characteristic equation by eliminating the coefficients of $C_{1}, C_{2}, C_{3}, C_{4}, C_{5}$, and $C_{6}$. For a non-trivial solution, the determinant of $[C]_{6 \times 6}$ must be equal to zero. The frequency parameter $k$ can be obtained by solving the characteristic equation via a simple root search method for a given set of $n, v, R_{11}, R_{22}$, and $b$. Using the mathematica software with symbolic competencies, the exact solutions to this problem are obtained. The numerical result of frequency parameter $k$ obtained from analysis is presented in a pictographic format. Poisson's ratio employed here is 0.3 . The frequency values for various magnitudes of $R_{22}$ and a constant $R_{11}\left(R_{11}=2\right)$ are tabulated in Table 1 . The values of frequency parameter $k$ for $n \leq 5$ modes with $R_{22}=0,2,4,6,8,10,25,50,100$, and $10^{16}$ and $R_{11}=2$ are obtained. For $b=1$ and $R_{22}=0$, the plate frequencies can be seen to be the same as those of the plate with no weakening crack.

For a given set of values of $b$ and $v$, the first frequency for a value of $n=0$, the modal frequency converges to that of the plate with no weakening as $R_{22}$ is increased starting from a value of 0 . When $v=0.3$, the first six frequencies of the plate with no weakening are obtained as $2.60309(n=0), 3.97077(n=1), 5.24447(n=2), 6.47023$ 
$\mathrm{T}$ a b 1 e 1

Fundamental Frequency Parameter $k$ for a Circular Hinge with $v=0.3, R_{22}=0$, and Different Values of $R_{11}$

\begin{tabular}{|c|c|c|c|c|c|c|c|c|c|c|c||}
\hline$b$ & 0 & 0.1 & 0.2 & 0.3 & 0.4 & 0.5 & 0.6 & 0.7 & 0.8 & 0.9 & 1.0 \\
\hline $\begin{array}{c}R_{11}= \\
=2\end{array}$ & 2.60312 & 2.56339 & 2.47855 & 2.40828 & 2.38445 & 2.41551 & 2.49588 & 2.58649 & 2.58137 & 2.43418 & 2.22145 \\
\hline $\begin{array}{c}R_{11}= \\
=10\end{array}$ & 2.95826 & 2.91071 & 2.81960 & 2.76548 & 2.78082 & 2.86027 & 2.94944 & 2.91290 & 2.71201 & 2.45934 & 2.22145 \\
\hline $\begin{array}{c}R_{11}= \\
=1000\end{array}$ & 3.19296 & 3.13583 & 3.03446 & 2.98881 & 3.03054 & 3.13626 & 3.18937 & 3.03205 & 2.74937 & 2.46594 & 2.22145 \\
\hline
\end{tabular}

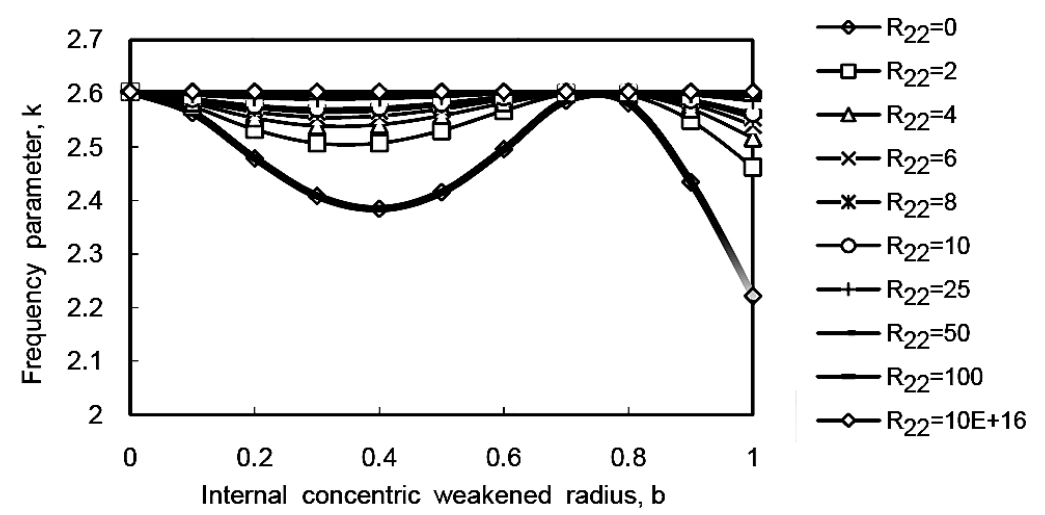

Fig. 2. The fundamental frequency and concentric weakened radius parameter for different $R_{22}$, $R_{11}=2, v=0.3$, and $n=0$.

$(n=3), 7.66549(n=4)$, and $8.8391(n=5)$. Noteworthy is that the fundamental frequency of the plate weakened along an internal concentric circle and resting on the elastically restrained edge against rotation and simply supported edge occurs at $n=0$ mode. The variation of the plate fundamental frequency for variable values of the weakened circle radius and the rotational restraint parameter of hinge is presented in Fig. 2. Here, frequency decreases with $R_{22}$, and is the lowest for $R_{22}=0$, which is a case of a frictionless circular hinge. The internal weakening decreases the fundamental frequency by 2.60309 , which makes it lower than that of a plate with no weakening by less than $15 \%(14.662 \%)$. For a given value of $R_{22}$, the frequency $k$ decreases from 2.60309 to 2.38445 , then increases to 2.58649 and finally drops to 2.22145 as the radius $b$ of the weakened circle varies from 0 to 1 . The local maximum frequency 2.60309 occurs at $b=0.7$. This is the optimal location, where the plate requires to be notched (as a closed hatch). The internal weakening has a minute effect, i.e., it decreases the fundamental frequency by less than $9 \%(8.4 \%)$ ] when $0 \leq b \leq 0.4$. Moreover, it has a more pronounced effect on the fundamental frequency, i.e., decreases the fundamental frequency by less than $15 \%$, when $b>0.7$.

The frequency values for various magnitudes of $R_{22}$ and a constant $R_{11} \quad\left(R_{11}=10\right)$ are tabulated in Table 1 . The first frequencies $(k)$ of $n \leq 5$ modes with $R_{22}=0,2,4,6,8$, $10,25,50,100$, and $10^{16}$ and $R_{11}=2$ are obtained. For $b=1$ and $R_{22}=0$, the plate frequencies are same as those of the plate with no weakening. For the given values of $b$ and $v$, the first frequency of $n=0$ mode converges to that of a plate with no weakening as $R_{22}$ increases from 0 . When $v=0.3$, the first six frequencies of the plate with no weakening are: $2.95829(n=0), 4.30618(n=1), 5.55404(n=2), 6.75602(n=3), 7.93028$ 
$(n=4)$, and $9.08575(n=5)$. Noteworthy is that the fundamental frequency of the plate weakened along an internal concentric circle and resting on the elastically restrained edge against rotation and simply supported edge occurs at $n=0$ mode. The plate fundamental frequencies varying with the radius of the weakened circle and the elastic rotational restraint of the hinge are presented in Fig. 3. The frequency decreases with $R_{22}$, and is the lowest for $R_{22}=0$, which is a case of a frictionless circular hinge. The internal weakening decreases the fundamental frequency by 2.95829 making it less than that of the plate with no weakening by $25 \%$.

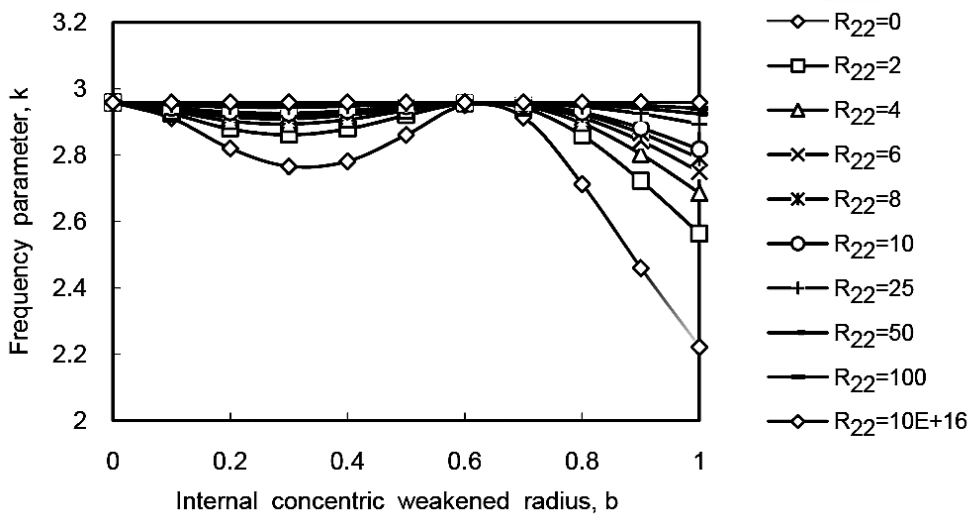

Fig. 3. The fundamental frequency and concentric weakened radius parameter for different $R_{22}$, $R_{11}=10, v=0.3$, and $n=0$.

For a given value of $R_{22}$, the frequency $k$ decreases from 2.95829 to 2.76548 , then increases to 2.94944 and finally drops to 2.22145 as the radius $b$ of the weakened circle varies from 0 to 1 . The local maximum frequency 2.95829 occurs at $b=0.6$. This is the optimum location where the plate needs to be notched. For $0 \leq b \leq 0.3$ the internal weakening has a feeble effect on the fundamental frequency, decreasing it by less than $7 \%$. A stronger effect on the fundamental frequency is observed for $b>0.6$ - it drops by less than $25 \%$. The plate higher-mode frequencies of plate varying with radius of the weakened circle and elastic rotational restraint of the hinge are presented in Figs. 4-8.

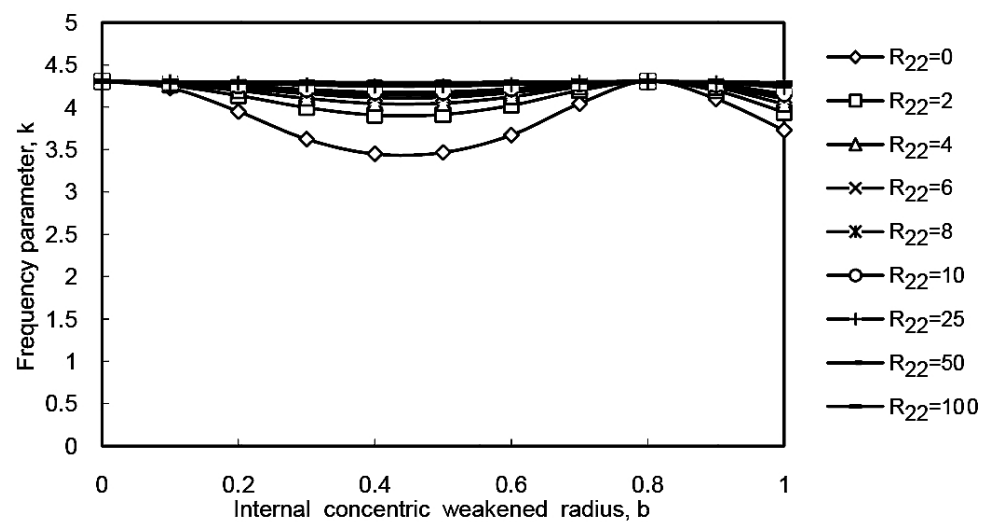

Fig. 4. The fundamental frequency and concentric weakened radius parameter for different $R_{22}$, $R_{11}=10, v=0.3$, and $n=1$.

The frequencies for various values of $R_{22}$ and constant $R_{11}\left(R_{11}=1000\right)$ are tabulated in Table 1. The first frequencies $(k)$ of $n \leq 5$ modes with $R_{22}=0,2,4,6,8,10$, 


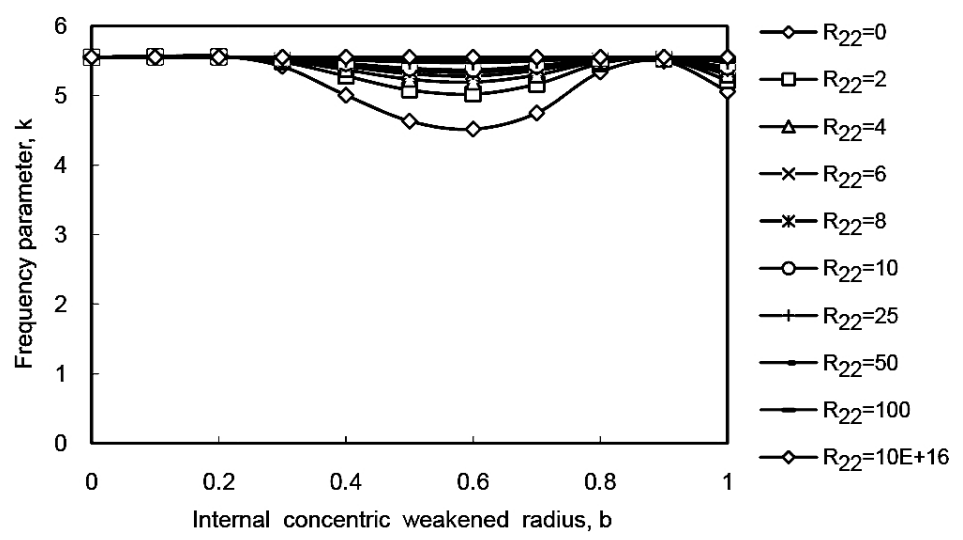

Fig. 5. The fundamental frequency and concentric weakened radius parameter for different $R_{22}$, $R_{11}=10, v=0.3$, and $n=2$.

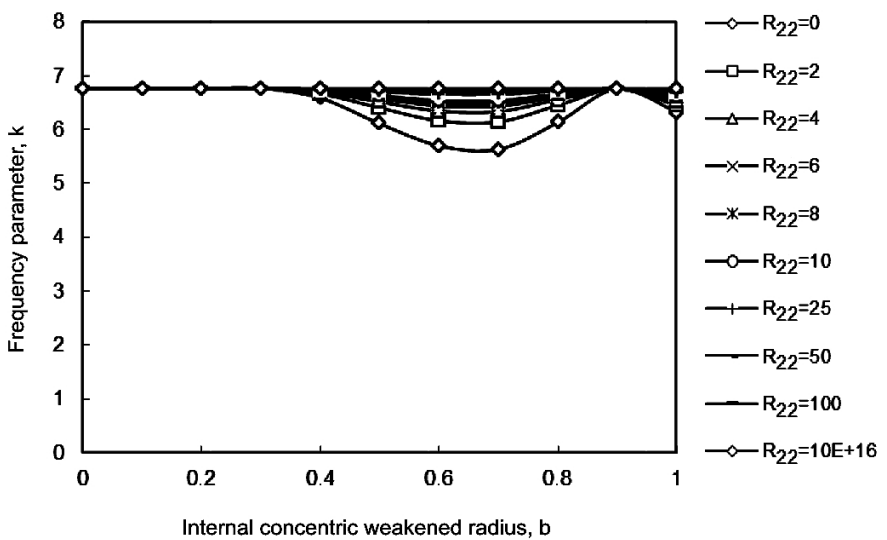

Fig. 6. The fundamental frequency and concentric weakened radius parameter for different $R_{22}$, $R_{11}=10, v=0.3$, and $n=3$.

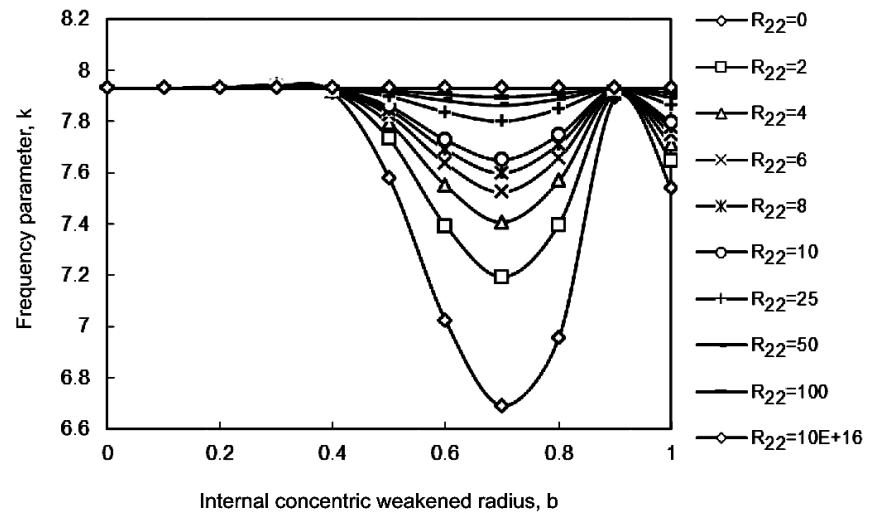

Fig. 7. The fundamental frequency and concentric weakened radius parameter for different $R_{22}$, $R_{11}=10, v=0.3$, and $n=4$.

$25,50,100$, and $10^{16}$ and $R_{11}=1000$ are determined. For $b=1$ and $R_{22}=0$, the plate frequency is equal that with no weakening. For the specified values of $b$ and $v$, the first frequency of $n=0$ mode converges to that with weakening as $R_{22}$ increases from 0 . 


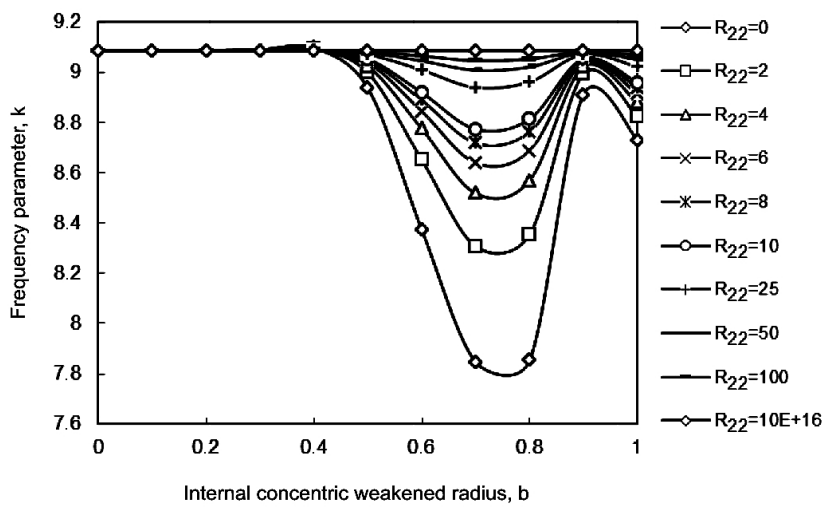

Fig. 8. The fundamental frequency and concentric weakened radius parameter for different $R_{22}$, $R_{11}=10, v=0.3$, and $n=5$.

When $v=0.3$, the first six frequencies of the plate with no weakening are: $3.19297(n=0)$, $4.60631(n=1), 5.89977(n=2), 7.13636(n=3), 8.33825(n=4)$, and $9.51625(n=5)$. It is observed that the fundamental frequency of the plate weakened along an internal concentric circle and resting on elastically restrained edge against rotation and simply supported edge occurs at $n=0$ mode.

The plate fundamental frequency variations with the radius of weakened circle and elastic rotational restraint of the hinge are presented in Fig. 9, where frequency decreases with $R_{22}$, and is the lowest for $R_{22}=0$, which is a case of a frictionless circular hinge. Here, the internal weakening decreases the fundamental frequency 3.19297 that is less than that with no weakening by $31 \%$. For the given value of $R_{22}$, the frequency decreases from 3.19297 to 2.98881 , then increases to 3.18937 , and finally drops to 2.22145 , as the radius $b$ of the weakened circle varies from 0 to 1 . The local maximum frequency 3.19297 occurs at $b=0.6$. This is the optimum location where the plate needs to be notched. The internal weakening has a feeble effect on the fundamental frequency (drops it by less than $7 \%$ ) when $0 \leq b \leq 0.3$. For the case of $b>0.6$, the fundamental frequency drops drastically (by $31 \%)$.

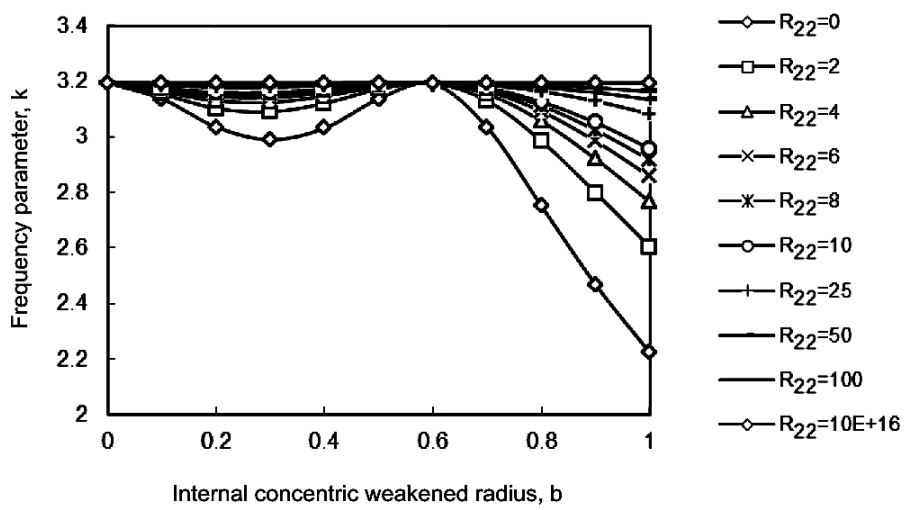

Fig. 9. The fundamental frequency and concentric weakened radius parameter for different $R_{22}$, $R_{11}=1000, v=0.3$, and $n=0$.

In all above-discussed cases, if $b=1$, the system is reduced to the case of a circular plate with elastic edge restraints. A fundamental frequency for the case of $R_{22}=0$, which models a through circular crack, is tabulated in Table 1. 
To the best of the authors' knowledge, the results for a circular plate with rotationally restrained and simply supported boundary presented here, are quite new and, hence, can be compared only with those available for the classical boundary conditions, such as simply supported and clamped plate [38] by setting the rotational restraint with $R_{11} \rightarrow 0$ and $R_{11} \rightarrow \infty$, respectively, as well as non-classical boundaries, such as a plate with an edge, which is elastically restrained from translation [44] with $R_{11} \rightarrow \infty$ by setting $R_{11} \rightarrow 0$. Here, the internal weakening decreases the fundamental frequency by less than $1 \%$ for the clamped plate and less than $1 \%$ when $b$ is 0 or 1 for the simply supported plate.

Conclusions. The circular plate frequency variation versus the values of elastic rotational restraint, elastic rotational restraint of hinge and the radius of the weakened circle is determined. The crack-induced internal weakening of a plate with elastically restrained rotation and simply supported edge is found to decrease the fundamental frequency by less than $15 \%$ for to $R_{11}=2$, about $25 \%$ for $R_{11}=10$ and $31 \%$ for $R_{11}=1000$. It is observed that internal weakening provides a stronger reduction of the fundamental frequency at higher values of elastic rotational restraint: at $R_{11}=2$ the respective drop is $14.662 \%$, whereas at $R_{11}=1000$ it is $30.4266 \%$. In addition, frequencies are obtained for different rotational parameters: a clamped boundary is simulated by $R_{11} \rightarrow \infty$ and a simply supported boundary by $R_{11} \rightarrow 0$. Accuracy of the results obtained is provided by the closed form of the proposed solution.

\section{Резюме}

Отримано точний розв'язок для опису коливань шарнірно закріпленої по зовнішньому краю кругової пластини з обмеженням по обертанню, яка послаблена круговою тріщиною. Розраховано частоти шести перших мод коливань пластини для різних значень пружних характеристик шарнірного затиснення, радіуса кругової тріщини та міри послаблення пластини тріщиною. Наявність тріщини моделюється у вигляді фіктивного пружного закріплення пластини по лінії тріщини. Показано, що послаблення пластини тріщиною призводить до зниження власної частоти коливань на 30\%. Припускається, що використання результатів точного розв'язку є перспективним при оцінці впливу тріщини на коливання кругової пластини із зовнішнім шарнірним закріпленням і обмеженням по обертанню та верифікації даних, що отримані наближеними числовими методами, включаючи з метод скінченних елементів.

1. S. Timoshenko and S. Woinowsky-Krieger, Theory of Plates and Shells, McGrawHill, New York (1959).

2. A. J. Mcleod and R. E. D. Bishop, The Forced Vibration of Circular Flat Plates, Institution of Mechanical Engineers, London (1965), pp. 1-33.

3. A. W. Leissa, Vibration of Plates, NASA SP-160 (1969).

4. A. W. Leissa, "Recent research in plate vibrations: classical theory," Shock Vibr. Dig., 9, No. 10, 13-24 (1977).

5. R. Szilard, Theory and Analysis of Plates, Prentice-Hall, New Jersey (1974).

6. M. Amabili, Nonlinear Vibrations and Stability of Shells and Plates, Cambridge University Press, New York (2008).

7. S. Azimi, "Free vibration of circular plates with elastic or rigid interior support," $J$. Sound Vibr., 120, 37-52 (1988).

8. G. N. Weisensel, "Natural frequency information for circular and annular plates," $J$. Sound Vibr., 133, 129-134 (1989).

9. C. Y. Wang and C. M. Wang, "Fundamental frequencies of circular plates with internal elastic ring support," J. Sound Vibr., 263, 1071-1078 (2003). 
10. P. Cawley and R. D. Adams, "The location of defects in structures from measurements of natural frequencies," J. Strain Anal. Eng. Des., 14, $49-57$ (1979).

11. K. Markström and B. Storákers, "Buckling of cracked members under tension," Int. J. Solids Struct., 16, 217-229 (1980).

12. B. D. Aggarwala and P. D. Ariel, "Vibration and bending of a cracked plate," Eng. Trans., 29, 295-310 (1981).

13. A. W. Leissa, O. G. McGee, and C. S. Huang, "Vibrations of circular plates having V-notches or sharp radial cracks," J. Sound Vibr., 161, 227-239 (1993).

14. O. G. Mcgee, A. W. Leissa, C. S. Huang, and J. W. Kim, "Vibration of circular plates with clamped V-notches or rigidly constrained radial cracks," J. Sound Vibr., 181, 185-201 (1995).

15. J. Yuan and S. M. Dickinson, "On the vibration of annular, circular and sectorial plates with cut-outs or on partial supports," Comput. Struct., 58, 1261-1264 (1996).

16. B. J. E. van Rens, W. A. M. Brekelmans, and F. P. T. Baaijens, "Homogenization of the elastoplastic behavior of perforated plates," Comput. Struct., 69, 537-545 (1998).

17. C.-H. Huang and C.-C. Ma, "Vibration of cracked circular plates at resonance frequencies," J. Sound Vibr., 236, 637-656 (2000).

18. M. Krawczuk, A. Zak, and W. Ostachowicz, "Finite element model of plate with elasto-plastic through crack," Comput. Struct., 79, 519-532 (2001).

19. T. Y. Li, J. X. Liu, and T. Zhang, "Vibrational power flow characteristics of circular plate structures with peripheral surface crack," J. Sound Vibr., 276, 1081-1091 (2004).

20. H. W. Shi, Z. Y. Shang, M. Guo, and H. Tian, "On the vibration frequencies of a circular plate with an artificial crack in water based on finite element method," Chinese J. Mech. Eng., 40, 142-146 (2004).

21. J. W. Kim and H. Y. Jung, "Influence of stress singularities on the vibration of rhombic plates with V-notches or sharp cracks," Key Eng. Mater., 270-273, 1414 1419 (2004).

22. A. Demir and V. Mermertas, "A study on annular plates with radial through cracks by means of sector type element," J. Sound Vibr., 300, 466-478 (2007).

23. A. Demir and V. Mermertas, "Natural frequencies of annular plates with circumferential cracks by means of sector type element," Eng. Fract. Mech., 75, 1143-1155 (2008).

24. C. S. Huang and A. W. Leissa, "Vibration analysis of rectangular plates with side cracks via the Ritz method," J. Sound Vibr., 323, 974-988 (2009).

25. T. Liu, K. Wang, Q. W. Dong, and M. S. Liu, "Hydroelastic natural vibrations of perforated plates with cracks," Proc. Eng., 1, 129-133 (2009).

26. C. S. Huang, A. W. Leissa, andR. S. Li, "Accurate vibration analysis of thick cracked rectangular plates," J. Sound Vibr., 330, 2079-2093 (2011).

27. X. H. Si, W. X. Lu, and F. L. Chu, "Wet mode analysis of completely clamped circular plate with a side radial crack," J. Vibr. Eng., 24, 595-599 (2011).

28. X. H. Si, W. X. Lu, and F. L. Chu, "Modal analysis of circular plates with radial side cracks and in contact with water on one side based on the Rayleigh-Ritz method," $J$. Sound Vibr., 331, 231-251 (2012).

29. X. H. Si, W. X. Lu, F. L. Chu, "Dynamic analysis of rectangular plates with a single side crack and in contact with water on one side based on the Rayleigh-Ritz method," J. Fluid Struct., 34, 90-104 (2012). 
30. L. H. Chen, Y. Sun, and W. Zhang, "Study of vibration characteristics of cantilever rectangular plate with side crack," Appl. Mech. Mater., 226-228, 113-118 (2012).

31. J. T. Chen, S. Y. Lin, I. L. Chen, and Y. T. Lee, "Mathematical analysis and numerical study of true and spurious eigenequations for free vibration of plates using imaginary-part BEM," J. Sound Vibr., 293, 380-408 (2006).

32. J. T. Chen, S. Y. Lin, I. L. Chen, and Y. T. Lee, "Mathematical analysis and numerical study for free vibration of annular plates using BIEM and BEM," Int. J. Numer. Meth. Eng., 65, 236-263 (2006).

33. W. M. Lee and J. T. Chen, "Analytical study and numerical experiments of true and spurious eigensolutions of free vibration of circular plates using real-part BEM," Eng. Anal. Bound. Elem., 32, 368-387 (2008).

34. W. M. Lee, J. T. Chen, and Y. T. Lee, "Free vibration analysis of circular plates with multiple circular holes using indirect BIEMs," J. Sound Vibr., 304, 811-830 (2007).

35. W. M. Lee and J. T. Chen, "Free vibration analysis of a circular plate with multiple circular holes by using multipole Trefftz method," Comput. Model. Eng. Sci., 50, 141-159 (2009).

36. W. M. Lee and J. T. Chen, "Eigensolutions of a circular plate with multiple circular holes by using the direct BIEM and addition theorem," Eng. Anal. Bound. Elem., 34, 1064-1071 (2010).

37. W. M. Lee and J. T. Chen, "Free vibration analysis of a circular plate with multiple circular holes by using addition theorem and indirect BIEM," J. Appl. Mech., 78, 1-10 (2011).

38. C. Y. Wang, "Fundamental frequency of a circular plate weakened along a concentric circle," J. Appl. Mathem. Mech., 82, 70-72 (2002).

39. L. H. Yu, "Frequencies of circular plate weakened along an internal concentric circle," Int. J. Struct. Stab. Dyn., 9, 179-185 (2009).

40. C. S. Kim and S. M. Dickinson, "The flexural vibration of the isotropic and polar orthotropic annular and circular plates with elastically restrained peripheries," $J$. Sound Vibr., 143, 171-179 (1990).

41. L. B. Rao and C. K. Rao, "Buckling of circular plates with a ring support and elastically restrained edge," Adv. Vibr. Eng., 8, 291-297 (2009).

42. C. Y. Wang and C. M. Wang, "Buckling of circular plates with an internal ring support and elastically restrained edges," Thin-Wall Struct., 39, 821-825 (2001).

43. L. Bhaskara Rao and C. Kameswara Rao, "Fundamental buckling of circular plates with elastically restrained edges and resting on concentric rigid ring support," Front. Mech. Eng., 8, 291-297 (2013).

44. L. Bhaskara Rao and C. Kameswara Rao, "Frequencies of circular plates weakened along an internal concentric circle and elastically restrained edge against translation," J. Appl. Mech., 80, No. 1, 011005 (2013). 